\title{
Bioaccumulation of mercury in invertebrate food webs of Canadian Rocky Mountain streams
}

\author{
K. J. Painter ${ }^{1,2}$, D. M. Janz ${ }^{1,3}$, and T. D. Jardine ${ }^{1,4}$ \\ ${ }^{1}$ University of Saskatchewan, Toxicology Centre, Saskatoon, Saskatchewan, Canada S7N 5B3
}

\begin{abstract}
Methylmercury (MeHg) is a contaminant of concern because of its ability to biomagnify in aquatic food webs, resulting in potentially harmful concentrations in higher consumers. Beaver impoundments in the southern Canadian Rockies release bioavailable $\mathrm{MeHg}$ to downstream food webs. We examined the magnitude of uptake and trophic transfer of exported $\mathrm{Hg}$ (total $\mathrm{Hg}$ [ $\mathrm{THg}]$ and $\mathrm{MeHg}$ ) to grazing and predatory invertebrates and controls on these transfers by site-specific (dissolved organic C [DOC], $\mathrm{MeHg}$ in water, $\mathrm{MeHg}$ in diet) and individual (body size, trophic level) variables. Bioconcentration factors (BCFs) were high (79,756 \pm $68,204)$ relative to values from the literature, declined with increasing $\mathrm{MeHg}$ in water, and did not differ above and below beaver ponds. Biomagnification factors (BMFs) for uptake from periphyton to grazers (18.3 \pm 11.7$)$ were high and increased with increasing DOC, BMFs from grazers to predators $(2.1 \pm 1.2)$ were low, and neither of these BMFs differed above and below ponds. Invertebrate body size had no effect on $\mathrm{MeHg}$ concentration. However, the relative difference in trophic level from prey to consumer was an important driver of BMFs, and MeHg in the diet was negatively associated with BMFs. Rates of uptake and transfer were greater at low than at higher concentrations, but overall trophic magnification through the food web (average trophic magnification factor $=2.3$ ) was on the lower end of the typical range observed worldwide. Thus, the limited risk to wildlife and humans who consume fish from these systems is a result, in part, of a dampening of bioaccumulation as it is transmitted through these invertebrate food webs that exhibit weak size structuring relative to other aquatic systems.
\end{abstract}

Key words: methylmercury, invertebrates, trophic transfer, streams, bioaccumulation, biomagnification, stable isotopes, food webs

Bioaccumulation, the process by which an organism attains a higher concentration of a chemical relative to its environment (Borgå et al. 2011), is highly variable among chemicals, organisms, and ecosystems. Bioaccumulation is a key endpoint criterion identified during hazard assessment, which traditionally attempts to define persistence, bioaccumulation, and toxicity (PBT). Bioconcentration and biomagnification are 2 components of bioaccumulation that are used to define rates of uptake and subsequent trophic transfer of a chemical. Bioconcentration in aquatic organisms is the uptake of a chemical across respiratory/dermal surfaces from the water. The bioconcentration factor (BCF) is the ratio of the concentration of a substance in a given organism to that in the water. Biomagnification is a special case of bioaccumulation that occurs when the chemical concentration is greater in an organism than in its prey because dietary absorption occurs faster than elimination (Borga et al. 2011). The biomagnification factor (BMF), sometimes called the trophic transfer factor (TTF; DeForest et al. 2007), is the ratio of the concentration of a substance in an organism to that in its diet (Gobas et al. 2009). The sum of these processes yields the bioaccumulation factor (BAF), the ratio of the concentration of a substance in an organism to that in the environment including both water and dietary sources (Gobas et al. 2009). BCF and BAF are bioconcentration and bioaccumulation endpoints that have been used in the development of environmental guidelines for risk assessment (Arnot and Gobas 2006). For example, Environment Canada identifies substances with BCF and BAF values $\geq 5000$ as bioaccumulative under the Canadian Environmental Protection Act (CEPA 1999).

Some trace elements, such as $\mathrm{Hg}$, are persistent in fresh waters, and their bioavailability is heavily influenced by geochemical factors (DeForest et al. 2007). Therefore, rates of $\mathrm{Hg}$ bioaccumulation are highly variable among locations (Lavoie et al. 2013) and defining critical PBT levels can be difficult (DeForest et al. 2007). For Hg and other trace elements, such as $\mathrm{Se}, \mathrm{Zn}, \mathrm{Cu}$, and $\mathrm{Pb}, \mathrm{BCF}$ s tend to be highest (indicating hazard) at low concentrations of exposure (low potential for toxicity) and lowest (indicating reduced haz-

E-mail addresses: ${ }^{2}$ kristin.painter@usask.ca; ${ }^{3}$ david.janz@usask.ca; ${ }^{4}$ To whom correspondence should be addressed, tim.jardine@usask.ca 
ard) at higher concentrations of exposure (high potential for toxicity). This tendency complicates risk assessments and suggests that exposure concentration may contribute as much as other metal- and species-specific determinants of bioaccumulation to BAFs (McGeer et al. 2003, DeForest et al. 2007). Therefore, BCFs and BAFs are important for describing the link between exposure concentrations and tissue concentrations. For example, high exposure concentrations may be of little consequence if the rate of transfer is low, leading to absent or minimal toxic effects.

$\mathrm{MeHg}$ is a potent neurotoxin with the potential to pose a serious health risk to humans and wildlife (Mergler et al. 2007). Thus, understanding the potential for MeHg to transfer from abiotic to biotic compartments and move further up the food web to higher trophic levels is imperative. Based on a large compilation of available data from peerreviewed literature and technical documents, DeForest et al. (2007) reported that BAFs for $\mathrm{MeHg}$ range from 100,000 to 48,000,000 across species and trophic levels, including invertebrates, small fish, and large fish. This wide range highlights the importance of understanding $\mathrm{MeHg}$ bioaccumulation and biomagnification and their contributing variables in aquatic systems.

Levels of $\mathrm{MeHg}$ are elevated in water downstream from impoundments (Roy et al. 2009), and this elevation leads to higher downstream concentrations in algae and invertebrates (Painter et al. 2015). Increases in MeHg concentration downstream from reservoirs, including North American beaver (Castor canadensis) impoundments, are thought to be the consequence of flooding of organic matter, which enhances microbial decomposition and, therefore, Hg methylation (St Louis et al. 2004, Roy et al. 2009). The magnitude of change from up- to downstream varies among ecological compartments and sites and ranges from a 0.5 to $2.5 \times$ increase in algae to a 0.6 to $5.0 \times$ increase in predatory invertebrates (Painter et al. 2015). These ranges indicate that other factors may modulate responses within the food web. For example, concentrations in water and the diet are inversely related to BCFs and BMFs, respectively, in laboratory and field studies (DeForest et al. 2007), and low pH can lead to higher BMFs in some organisms (Jardine et al. 2013).

Concentration of dissolved organic C (DOC), an indicator of wetland influence (Brigham et al. 2009, Chasar et al. 2009), explains additional variability in $\mathrm{MeHg}$ concentrations among sites (Painter et al. 2015), but relationships between DOC and $\mathrm{MeHg}$ transport and uptake are complex. For example, increased DOC concentrations in the water column of Adirondack lakes resulted in a negative correlation between DOC and BAF for Yellow Perch (Perca flavescens) (Dittman and Driscoll 2009). Dittman and Driscoll (2009) hypothesized that the negative correlation was caused by binding between DOC in the water column and $\mathrm{MeHg}$, which reduced the bioavailable pool. Other studies illustrate the importance of DOC in transporting $\mathrm{MeHg}$ into aquatic systems (Adams et al. 2009, Brigham et al.
2009). Positive correlations between DOC concentrations and $\mathrm{MeHg}$ in the water column (Brigham et al. 2009) and in basal foodweb organisms (Adams et al. 2009) are common. Therefore, how DOC controls uptake and transfer of $\mathrm{MeHg}$ should be investigated.

We measured uptake and accumulation of $\mathrm{MeHg}$ in stream food webs along a $\mathrm{MeHg}$ gradient (up- to downstream of beaver impoundments; Painter et al. 2015) by examining the movement of this trace element among environmental compartments (water, periphyton, and herbivorous and predatory invertebrates). We used BCFs, BAFs, and BMFs as described above, and we examined other aspects of the invertebrate food web that can influence $\mathrm{MeHg}$ concentrations. First, we assessed trophic transfer of $\mathrm{MeHg}$ with the aid of $\mathrm{N}$ stable-isotope ratios $\left({ }^{15} \mathrm{~N} /\right.$ ${ }^{14} \mathrm{~N}$; hereafter, $\delta^{15} \mathrm{~N}$ ) to identify feeding linkages in stream food webs. The habitat-independent, stepwise enrichment of ${ }^{15} \mathrm{~N}$ with trophic level has been used widely to characterize aquatic food webs (Minagawa and Wada 1984), and the relationship between $\delta^{15} \mathrm{~N}$ and environmental contaminants, such as $\mathrm{MeHg}$, has long been used as a predictor of contaminant biomagnification (Kidd et al. 1995). Second, we evaluated the relationship between body size, trophic level, and $\mathrm{MeHg}$ concentrations. Body size is directly correlated with $\mathrm{MeHg}$ concentrations in fishes because larger fishes tend to be older or feed at higher trophic levels (Kidd et al. 1995, Gewurtz et al. 2011). However, invertebrates are rarely classified based on their size in contaminant studies (Watanabe et al. 2008) because trophic-level estimates vary widely within functional feeding groups (Merritt and Cummins 1996). We expected positive relationships between $\delta^{15} \mathrm{~N}$, body size, and $\mathrm{MeHg}$ because predators are consistently larger than their prey (Riede et al. 2011) and because predators tend to occupy higher trophic levels than their prey (Anderson and Cabana 2009). Taken together, we sought to estimate the importance of physicochemical variables, such as DOC and $\mathrm{MeHg}$ concentrations in water and the diet, at the base of the food web and the relationships of these processes with bioconcentration and trophic transfer of $\mathrm{MeHg}$.

\section{METHODS}

\section{Field sampling and laboratory methods}

From mid-July to early August 2012, we used methods described by Painter et al. (2015) to sample 15 streams with in-channel beaver impoundments and 6 free-flowing streams assumed to be uninfluenced by beaver activity on the eastern slope of the Canadian Rocky Mountain and Foothill Regions, Alberta. The streams had no known local point sources of Hg. Most streams were in conifer-dominated watersheds at elevations of 1300 to $2150 \mathrm{~m}$. Sites had clear water, a high gradient with cobble and gravel substrates, moderately basic $\mathrm{pH}$, and limited accumulation of leaf litter because of low canopy cover, typically $<20 \%$ (Painter et al. 2015). At each sampling location, we collected water, 
periphyton, and aquatic macroinvertebrates. At dammed sites, collections were made immediately above and below the impoundment (i.e., at an inflow and an outflow). Samples for THg and $\mathrm{MeHg}$, DOC, total P (TP), and benthic chlorophyll $a$ (chl $a$ ) were collected, processed, and analyzed as described by Painter et al. (2015).

To assess body size, we sorted invertebrates, identified them to family level (Merritt and Cummins 1996), and counted and weighed them prior to drying them at $50^{\circ} \mathrm{C}$ for $48 \mathrm{~h}$. When they were dry, we weighed invertebrates again and homogenized them using an acid-washed glass mortar and pestle. We calculated invertebrate body size as the average wet mass of individuals from 3 replicate samples collected at each site. We analyzed homogenized samples of taxa dominant across all sites, including grazing mayflies from the families Heptageniidae, Ephemerellidae, and Baetidae and predatory invertebrates from the families Perlodidae and Rhyacophilidae, as pooled samples for $\mathrm{THg}$ and $\mathrm{MeHg}$ and stable isotopes (see Painter et al. 2015 for detailed methods and quality assurance/quality control). We also analyzed all organisms collected from upstream and downstream locations at 2 beaver-affected sites (hereafter, comprehensive foodweb sites) to develop an understanding of $\mathrm{MeHg}$ behavior in more comprehensive invertebrate food webs in these systems. Additional taxa analyzed at those sites were Hydropsychidae, Limnephilidae, Phrygancidae, Tipulidae, Chironomidae, Siphlonuridae, Polycentropodidae, and Peltoperlidae.

\section{Calculations}

Uptake and trophic transfer are calculated as 3 factors: BCF, BMF, and BAF. BCF for animals can be measured only under controlled laboratory conditions (i.e., steady state) in which dietary uptake is deliberately excluded (Arnot and Gobas 2006, Gobas et al. 2009), but for autotrophs, such as periphyton with a single route of uptake, BCF can be calculated from field data as the ratio of the chemical concentration in the organism $\left(C_{B}\right)$ to the chemical concentration in the water $\left(C_{W}\right)$ as:

$$
\mathrm{BCF}=C_{B} / C_{W}
$$

Biomagnification is the process by which the thermodynamic activity of the chemical in an organism exceeds that in its diet (Gobas and Morrison 2000, Arnot and Gobas 2006). BMF for organometals, such as $\mathrm{MeHg}$, that are almost exclusively derived from the diet (Hall et al. $1997)$ is expressed as the ratio of $C_{B}$ to the concentration in the diet $\left(C_{D}\right)$ as:

$$
\mathrm{BMF}=C_{B} / C_{D}
$$

BMF $>1$ indicates that the chemical is a probable bioaccumulative substance (Gobas et al. 2009). For these analyses, we classified Heptageniidae, Ephemerellidae, and
Baetidae as herbivorous grazers, and Perlodidae and Rhyacophilidae as predatory taxa and assumed that each trophic level fed entirely on the trophic level below it. We pooled the 3 mayfly taxa, and we pooled the 2 predatory taxa because $\mathrm{MeHg}$ concentrations were not statistically different among taxa within these groups (Painter et al. 2015). We used stable $\mathrm{N}$ isotope data to confirm feeding linkages (described below) and to account for potential omnivory.

Bioaccumulation, the sum of all exposure routes for animals (Arnot and Gobas 2006), is expressed as:

$$
\mathrm{BAF}=C_{B} / C_{W}
$$

For chemicals with an octanol-water partition coefficient $\left(\log \mathrm{K}_{\mathrm{OW}}\right) \leq 5$, BCFs and BAFs $\leq 5000 \mathrm{~L} / \mathrm{kg}$ wet mass indicate absence of biomagnification potential in waterrespiring organisms (Gobas et al. 2009).

\section{Stable isotopes}

$\delta^{15} \mathrm{~N}$ increases with trophic level, so it can be used to compare $\mathrm{Hg}$ biomagnification across systems as the slope of the regression of log-transformed $\mathrm{MeHg}$ vs $\delta^{15} \mathrm{~N}$ or trophic level (Borgå et al. 2011, Lavoie et al. 2013). Calculation of a trophic-level value takes into consideration a trophic enrichment factor (TEF; increase in $\delta^{15} \mathrm{~N}$ from diet to consumer) and assigns a discrete trophic level (TL) to a baseline organism (e.g., periphyton TL $=1$ ) because $\delta^{15} \mathrm{~N}$ can vary widely among sites (Cabana and Rasmussen 1996). $\delta^{15} \mathrm{~N}$ was converted to trophic level as:

$$
\mathrm{TL}_{\text {consumer }}=\frac{\delta^{15} \mathrm{~N}_{\text {consumer }}-\delta^{15} \mathrm{~N}_{\text {baseline }}}{\mathrm{TEF}}+\mathrm{TL}_{\text {baseline }}
$$

where $\mathrm{TL}_{\text {consumer }}=$ trophic level of the consumer and $\mathrm{TL}_{\text {baseline }}=$ trophic level of the baseline organism. We used periphyton as the baseline organism with $\mathrm{TL}=1$. We chose a TEF of $2.0 \%$ (McCutchan et al. 2003), a value suitable for stream food webs (Bunn et al. 2013, Jardine et al. 2013). In an analysis of 144 records across arid, tropical, subtropical, and temperate sites, Bunn et al. (2013) found that many TEF estimates for invertebrate food webs were lower than the commonly reported $3.4 \%$. We chose a $2.0 \%$ value based on similar TEFs from the literature for stream invertebrate food webs (McCutchan et al. 2003, Bunn et al. 2013).

Trophic magnification factors (TMFs) represent the average biomagnification per TL through the entire food web and are calculated as the antilog of the slope $(b)$ of a regression of logMeHg vs TL as follows (Borgå et al. 2011):

$$
\mathrm{TMF}=10^{b}
$$

When TMF $=1(b=0)$, MeHg does not biomagnify on average through the food web; when TMF $>1(b>0)$, 
MeHg biomagnifies through the food web by an average of TMF/TL; and when TMF $<1(b<0)$, MeHg decreases by an average of TMF/TL (Borgå et al. 2011).

Trophic magnification slopes (TMSs) also can be derived directly from the $\log \mathrm{MeHg}$ vs $\delta^{15} \mathrm{~N}$ regression and can be compared across systems without standardizing to a baseline (Lavoie et al. 2013). The TMS is calculated as the slope $(b)$ in the following model:

$$
\log \mathrm{MeHg}=b \delta^{15} \mathrm{~N}+a
$$

No change in $\log \mathrm{MeHg}$ concentration with increasing $\delta^{15} \mathrm{~N}$ produces TMS $=0$, which indicates no biomagnification. An increase in $\log \mathrm{MeHg}$ concentration with increasing $\delta^{15} \mathrm{~N}$ produces TMS $>0$, which indicates biomagnification. A decrease of $\log \mathrm{MeHg}$ concentration with increasing $\delta^{15} \mathrm{~N}$ produces TMS $<0$, which indicates trophic dilution, the opposite of biomagnification (Gobas et al. 2009).

We were able to calculate BCFs, BAFs, and BMFs for all 36 sites (hereafter, expressed as log-transformed values unless otherwise specified). However, a regression model for each site is needed to calculate TMSs and TMFs. Our sample size within sites was too small to calculate regressions, except at up- and downstream locations at the 2 comprehensive foodweb sites. Instead, we calculated overall TMF values for all sites combined into a single regression and then back-calculated TMS to compare to other studies (Lavoie et al. 2013) by dividing logMeHg vs TL slopes by the TEF.

\section{Data analysis}

We used paired $t$-tests to compare BCFs, BAFs, and BMFs between up- and downstream locations at all beaveraffected sites. We used linear regressions to show the strength of associations between individual variables and bioaccumulation measures. Regressions were carried out using upstream and free-flowing sites for BCFs and BMFs vs dietary $\mathrm{MeHg}$ and $\mathrm{DOC}$, and for BMFs vs $\mathrm{TL}_{\text {(consumer/prey). }}$. This latter measure is calculated by dividing TL of a consumer by that of its presumed diet and includes both $\mathrm{TL}_{\text {(grazers/periphyton) }}$ and $\mathrm{TL}_{\text {(predators/grazers) }}$. We used linear regression analysis to assess the strengths of associations between $\mathrm{MeHg}$ and invertebrate body size, TL and body size, $\mathrm{MeHg}$ and TL, and to measure the MeHg vs $\delta^{15} \mathrm{~N}$ relationship at the comprehensive foodweb sites.

A large proportion (58\%) of $\mathrm{MeHg}$ observations were below the detection limit (BDL; $0.02 \mathrm{ng} / \mathrm{L}$ ) in our water samples. We used robust regression on order statistics (ROS), a semiparametric method ideal for data sets with a small sample size $(n<50)$ and only a single detection limit (Helsel 2005), to compute summary statistics for $\mathrm{MeHg}$ concentrations in water. Mean and standard error (SE) calculated by robust ROS $(0.031 \pm 0.0043)$ were very similar to those calculated by replacing BDL values with the $1 / 2$ detection limit value of $0.01 \mathrm{ng} / \mathrm{L}(0.029 \pm 0.0045)$. Therefore, we used the $1 / 2$ detection limit value to calculate BCFs.

We used an information theoretic (IT) approach to examine variables that might explain among-site variability in uptake and trophic transfer (Burnham and Anderson 2002, Giam and Olden 2015). We used Akaike's Information Criterion (AIC) to compare and rank competing regression models to identify the best approximating model or set of models. Initial screening of data before AIC analysis suggested that up- and downstream values were similar at beaver-affected sites. Therefore, we used only upstream data to conduct the AIC analysis. We combined data for upstream locations of beaver-affected streams with data from free-flowing streams (model sets A and B). We did not conduct AIC analysis on BCFs because many sites had BDL water MeHg concentrations.

We developed model sets for $\mathrm{BMF}_{\text {(grazers/periphyton) }}$ and $\mathrm{BMF}_{\text {(predators/grazers) }}$ and included variables selected a priori because they were likely to influence BMF. These variables included $\mathrm{MeHg}_{\text {diet }}$ (DeForest et al. 2007, Jardine et al. 2013), DOC (Chasar et al. 2009), TP (Lavoie et al. 2013), and benthic chl $a$ (Lavoie et al. 2013) and the relative difference in TL between prey and consumer, calculated as $\mathrm{TL}_{\text {(consumer/prey) }}$ (Fisk et al. 2001). We could not test for the effects of $\mathrm{pH}$ (Jardine et al. 2013) because the range of values at our study sites was limited (7.8-8.4). We used AIC corrected for small sample size (AICc) as described by Painter et al. (2015) because of the small sample size $(n)$ and small $n / k$, where $k$ is the number of fitted parameters. No single model was overwhelmingly supported (Akaike weight $>0.9$ ), so we used model averaging to reduce model selection uncertainty (Burnham and Anderson 2002). We calculated model-averaged parameter estimates (in this case, regression coefficients) and corresponding SEs according to Burnham and Anderson (2002). We also calculated partitioned- $R^{2}$-based relative variable importance (RVI) metrics to assess the importance of individual parameters. These metrics use hierarchical partitioning of $R^{2}$ among explanatory variables by averaging the increase in model $R^{2}$ when each variable is added across all possible orders of the model. We report 2 RVI metrics, $I_{\text {global }}$ and $I_{\text {weighted }}$, and the model-averaged parameter estimates, as recommended by Giam and Olden (2015).

$I_{\text {global }}$ is the variance partitioned among a single model containing all hypothesized explanatory variables (the global model). This approach does not account for model selection uncertainty and incorporates all variables without considering the possibility that a particular variable is spurious. Hierarchical partitioning can be carried out in a multimodel IT framework to account for these issues. $I_{\text {weighted }}$ is the model probability-weighted variable importance for a given explanatory variable. For each of the $K$ models, the independent effects $\left(I x_{j, k}\right)$ of the candidate explanatory variables are calculated. Variables not present in the given model are assigned $I=0$. Therefore, $I$ can be 


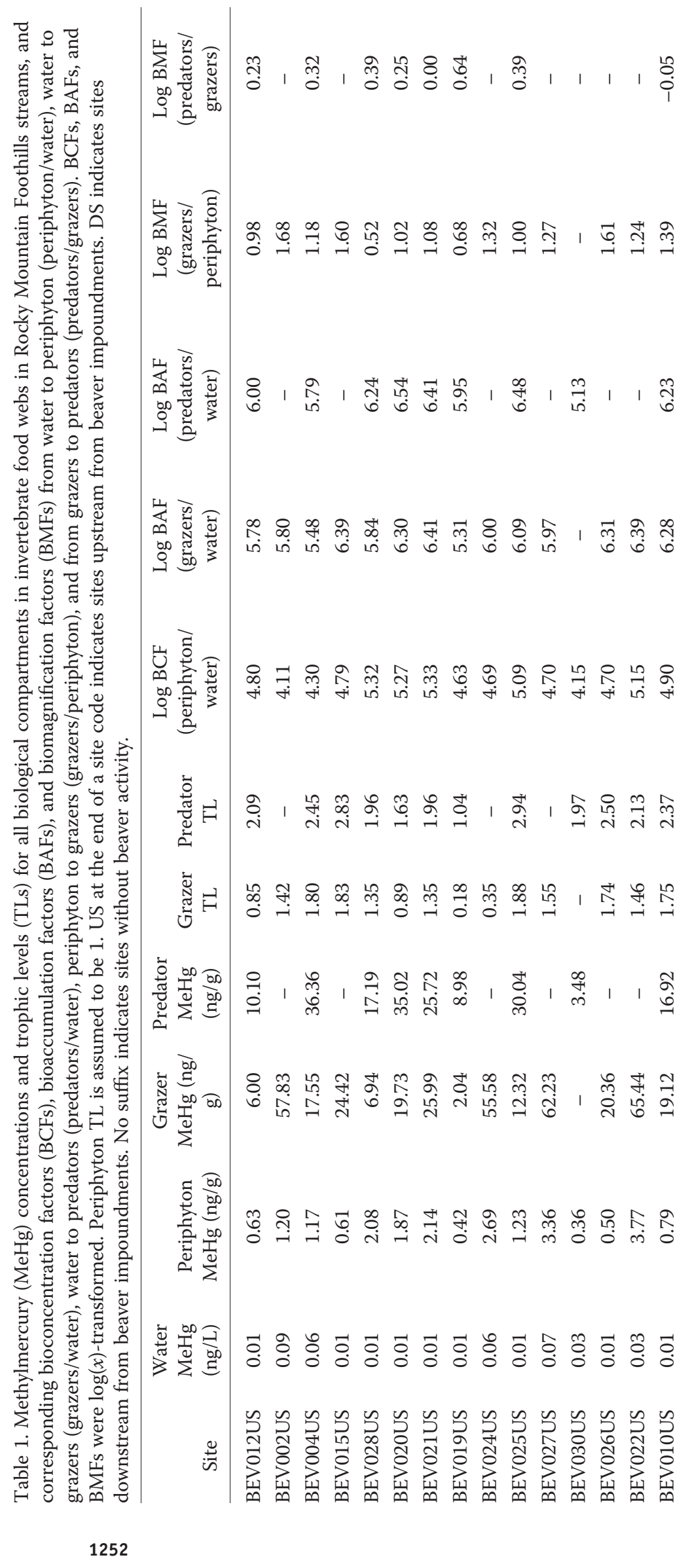




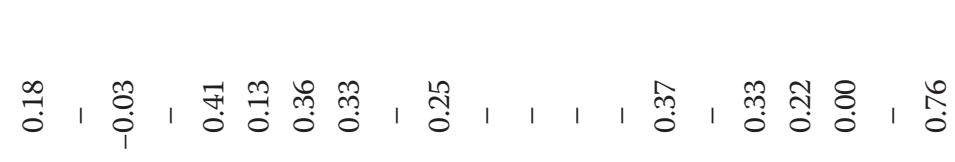

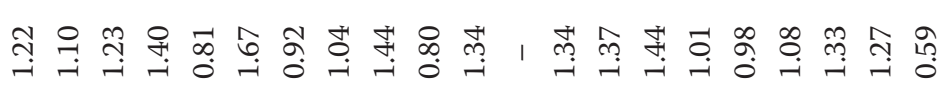

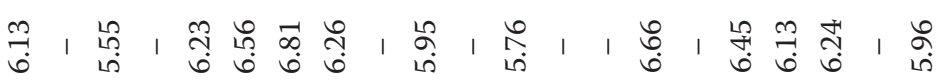

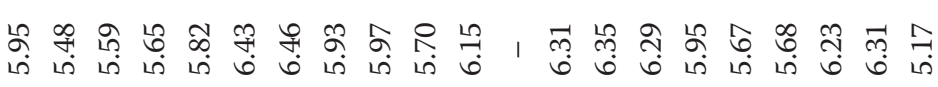

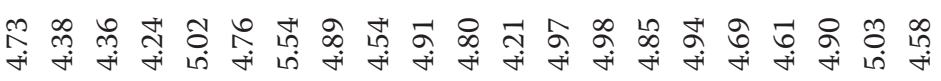

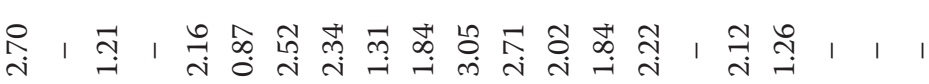

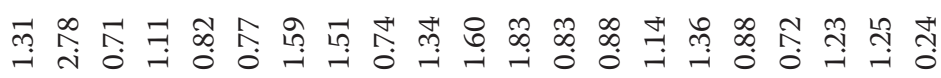

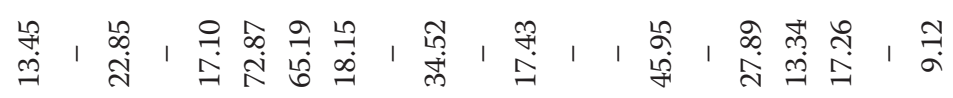

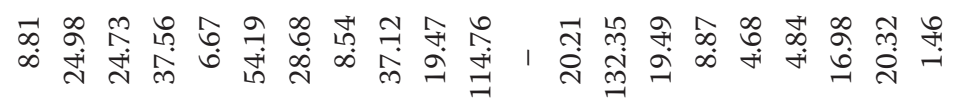

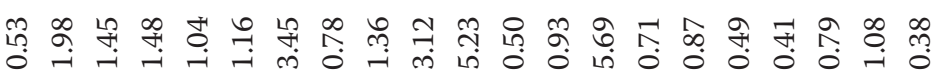

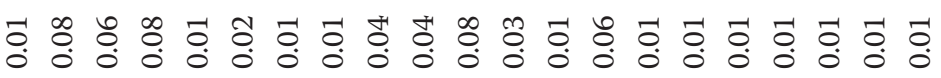

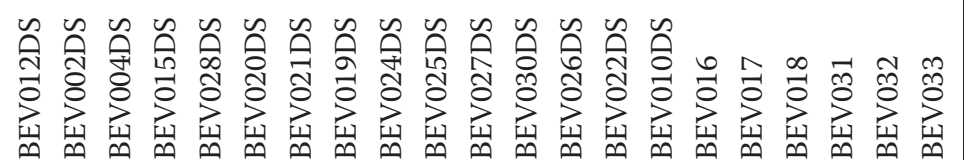


described as the independent effect of variable $x_{j}$ given that model $k$ is the best approximating model. To incorporate uncertainty in the best approximating model, $I_{\text {weighted }}$ is calculated as:

$$
I_{\text {weighted }(x j)}=\sum_{k=1}^{K} w_{k} I_{x j, k}
$$

where $w_{k}$ is the model weight as calculated from the AIC. Giam and Olden (2015) recommended reporting both metrics because $I_{\text {weighted }}$ attenuates the reduction in precision and increase in bias introduced by the incorrect inclusion/exclusion of spurious/genuine variables when the global model is used, whereas $I_{\text {global }}$ exhibits greater accuracy and precision in estimating the importance of stronger explanatory variables. $I_{\text {global }}$ also is favored in the case of small data sets with correlated explanatory variables.

We carried out statistical analyses with SYSTAT (version 13; Systat Software, San José, California) and R (version 3.2.2; R Project for Statistical Computing, Vienna, Austria) using the NADA package (Lee 2013) for the robust ROS and the relaimpo package (Grömping 2015) for RVI metrics. All data except TL were $\log (x)$-transformed prior to all of the above analyses.

\section{RESULTS}

\section{General bioaccumulation trends}

BCFs were in the upper $1 / 2$ of the distribution of literature values for fresh waters, whereas BMFs and BAFs were generally low compared with values published in the literature (Table 1). Untransformed BCFs ranged from $\sim 12,000$ to 344,000 , and untransformed BMFs ranged from $\sim 3.8$ to 48 for $\mathrm{BMF}_{\text {(grazers/periphyton) }}$ and 0.9 to 10 for $\mathrm{BMF}_{\text {(predators/grazers). }}$ BCFs, BAFs, and BMFs $(\log [x]$ transformed) did not differ between up- and downstream locations at beaver-affected sites ( $p>0.05$ for all comparisons; Table 2).

Mean $\delta^{15} \mathrm{~N}$ values were $2.5 \pm 1.5 \%$ o in periphyton, $3.0 \pm 1.6 \%$ in grazing mayflies and $4.4 \pm 1.5 \%$ in predatory invertebrates resulting in low TLs for mayflies and predators of $1.2 \pm 0.5$ and $2.1 \pm 0.6$, respectively. The slope of the $\log \mathrm{MeHg}$ vs TL regression for all 21 sites combined was 0.34 and the slope of the $\log \mathrm{THg}$ vs TL regression was 0.08 (Fig. 1), resulting in TMFs of 2.3 for $\mathrm{MeHg}$ and 1.2 for THg. These values correspond to TMSs of 0.18 for $\mathrm{MeHg}$ and 0.03 for THg. At the 2 comprehensive foodweb sites, MeHg TMSs were higher up- (BEV004US TMS $=0.33$, BEV028US TMS $=0.27$ ) than downstream $($ BEV004DS TMS $=-0.01$, BEV028DS TMS $=0.14)$ from beaver impoundments despite higher overall concentrations downstream (Fig. 2A, B). These relationships were not significant for 3 of 4 regressions (BEV004US: $r^{2}=0.61, p=$ 0.022; BEV028US: $r^{2}<0.01, p=0.957$; BEV004DS: $r^{2}=$ 0.39, $p=0.099$; BEV028DS: $r^{2}=0.21, p=0.182$ ). Confi- dence intervals (CIs) around slope estimates overlapped because of high variability and low sample size.

Variables contributing to $\mathrm{Hg}$ transfer within food webs

The $\log \mathrm{MeHg}$ vs log-transformed mean body size (slope $=-0.039, r^{2}<0.01, p=0.764$; Fig. 3A) and the TL vs body size (slope $=0.113, r^{2}=0.02, p=0.109$; Fig. 3B) relationships were not significant. The logMeHg vs TL relationship was weak but significant (slope = 0.137, $r^{2}=0.06, p=0.004$; Fig. 3C).

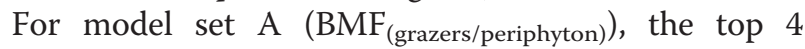
models had $\Delta \leq 2$. The best model contained only

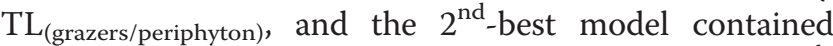
$\mathrm{TL}_{\text {(grazers/periphyton) }}$ and DOC. Evidence ratios (ERs) of the $2^{\text {nd }}$ best model was only 1.034, suggesting almost equal weight between the 2 top models (Table 3 ). $\mathrm{TL}_{\text {(grazers/periphyton) }}$ and DOC had the strongest averaged parameter estimates $(0.287 \pm 0.121$ and $0.381 \pm 0.199$, respectively). The averaged parameter estimates of $\mathrm{MeHg}_{\text {diet }}$ (periphyton $\mathrm{MeHg}$ concentration), TP, and chl $a$ were $-0.317 \pm 0.379,-0.296 \pm$ 0.250 , and $0.047 \pm 0.116$, respectively, but the large SEs made them weak predictors of $\mathrm{BMF}_{\text {(grazers/periphyton). The }}$ intercept-only (null) model had a $\Delta=3.9$, making it a plausible model, but the top 4 models had a summed weight of 0.809 (accounted for $80.9 \%$ of the weight in the set) compared to only $3.7 \%$ for the intercept-only model. RVI metrics showed that the largest proportion of variance was accounted for by $\mathrm{TL}_{\text {(grazers/periphyton) }}$ and DOC (Table 4). The total variance explained was $33.4 \%$ for the $I_{\text {weighted }}$ model parameters and $48.7 \%$ for the $I_{\text {global }}$ model parameters.

For model set $\mathrm{B}\left(\mathrm{BMF}_{(\text {predators/grazers })}\right)$, the top 2 models had $\triangle \mathrm{AIC} \leq 2$ (Table 3 ). The top model contained $\mathrm{MeHg}_{\text {diet }}$ (here, grazer $\mathrm{MeHg}$ concentration) and DOC, and the $2^{\text {nd }}$ best model contained $\mathrm{MeHg}_{\text {diet, }}$ DOC, and benthic chl $a$. $\mathrm{MeHg}_{\text {diet }}$ and DOC had the strongest averaged parameter estimates $(-0.631 \pm 0.107$ and $0.379 \pm 0.119$, respectively). The averaged parameter estimates for chl $a$ and TL (predators/grazers) were $0.120 \pm 0.055$ and $0.084 \pm 0.035$, respectively, and TP had no support. The largest proportion of variance was accounted for by $\mathrm{MeHg}_{\text {diet. }}$. In the global model that accounted for $85.7 \%$ of the total variance, $79.7 \%$ was partitioned among

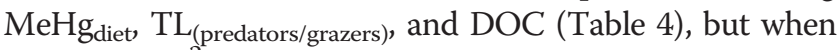
partitioned- $R^{2}$ was weighted, most of the variance $(74.4 \%$ of the total $83.8 \%$ ) was explained by $\mathrm{MeHg}_{\text {diet, }}$ reflecting the estimated top model. This finding could be a case of a weak correlation between explanatory variables in which the variance of the stronger variable $\left(\mathrm{MeHg}_{\text {diet }}\right)$ was overestimated by $I_{\text {weighted }}$. As such, results of both $I_{\text {global }}$ and $I_{\text {weighted }}$ should be considered.

Results of regressions between bioaccumulation measures and individual $\mathrm{MeHg}$ transfer variables (Fig. 4A-H) confirmed significant relationships $(p<0.05)$ between $\mathrm{BCF}_{\text {(periphyton/water) }}$ and water $\mathrm{MeHg}\left(r^{2}=0.31, p=0.008\right.$; Fig. 4A), $\mathrm{BMF}_{\text {(predators/grazers) }}$ and $\mathrm{MeHg}_{\text {grazers }}\left(r^{2}=0.68, p=\right.$ 
Table 2. Mean $( \pm$ SE) upstream and downstream $\log (x)$ transformed bioaccumulation measures (as described in Table 1) at beaver-affected sites.

\begin{tabular}{lcc}
\hline Bioaccumulation measure & Upstream & Downstream \\
\hline $\log \mathrm{BCF}_{\text {(periphyton/grazers) }}$ & $4.79 \pm 0.10$ & $4.74 \pm 0.09$ \\
$\log \mathrm{BAF}_{\text {(grazers/water) }}$ & $6.02 \pm 0.09$ & $6.00 \pm 0.09$ \\
$\log \mathrm{BAF}_{\text {(predators/water) }}$ & $6.09 \pm 0.15$ & $6.21 \pm 0.14$ \\
$\log \mathrm{BMF}_{\text {(grazers/periphyton) }}$ & $1.18 \pm 0.09$ & $1.22 \pm 0.07$ \\
$\log \mathrm{BMF}_{\text {(predators/grazers) }}$ & $0.27 \pm 0.08$ & $0.25 \pm 0.05$ \\
\hline
\end{tabular}

0.001; Fig. 4C), and $\mathrm{BMF}_{\text {(grazers/periphyton) }}$ and DOC $\left(r^{2}=\right.$ $0.22, p=0.038$; Fig. 4E). Relationships also were significant for BMFs and consumer TLs relative to their prey: $\mathrm{BMF}_{\text {(grazers/periphyton) }}$ vs $\mathrm{TL}_{\text {(grazers/periphyton) }}\left(r^{2}=0.29, p=\right.$ 0.015; Fig. 4G) and $\mathrm{BMF}_{\text {(predators/grazers) }}$ vs $\mathrm{TL}_{\text {(predators/grazers) }}$ $\left(r^{2}=0.46, p=0.030\right.$; Fig. $\left.4 \mathrm{H}\right)$. Regressions explained little variability between $\mathrm{BMF}_{\text {(grazers/periphyton) }}$ and periphyton $\mathrm{MeHg}$ concentration $\left(r^{2}=0.01, p=0.619\right.$; Fig. $\left.4 \mathrm{~B}\right)$, $\mathrm{BCF}_{\text {(grazers/periphyton) }}$ and DOC $\left(r^{2}=0.004, p=0.780\right.$; Fig. 4D), and $\mathrm{BMF}_{\text {(predators/grazers) }}$ and DOC $\left(r^{2}=0.01\right.$, $p=0.937$; Fig. 4F).

\section{DISCUSSION}

Our work adds to the growing body of knowledge about how $\mathrm{Hg}$ liberated by beaver impoundments is modified as it is transferred through food webs and offers an important contrast to work carried out at low-pH, high-nutrient streams in well vegetated watersheds (e.g., Roy et al. 2009). $\mathrm{MeHg}$ uptake from abiotic to biotic compartments was high, but rates of transfer within the invertebrate food webs of these Rocky Mountain streams were low. Mean untransformed BCFs were 79,756 $\pm 68,204$, which are high compared to literature values for $\mathrm{MeHg}$ reported by McGeer et al. (2003) for a range of organisms including algae, invertebrates, and fish $(8952 \pm 24,675 ; n=53)$. Our values probably are not indicative of hazard of toxicity but instead reflect natural conditions in which uptake is high when ambient concentrations are low (DeForest et al. 2007, Cardwell et al. 2013). Bioaccumulation factors (mean $\mathrm{BAF}_{\text {(grazers/water) }}=$ $1,259,951 \pm 838,812$, mean $\mathrm{BAF}_{\text {(predators/water) }}=1,969,288 \pm$ $1,541,130)$ were within the range of literature BAF values for $\mathrm{MeHg}$ reported by DeForest et al. (2007) (100,000$48,000,000)$, but rates of trophic transfer within the food web were low. Our calculated mean MeHg TMS (0.18) was near the global average for $\mathrm{MeHg}$ in freshwater systems $(0.24 \pm 0.08)$, but our calculated TMS for THg (0.03) was well below the global average for $\mathrm{THg}$ in fresh water $(0.15 \pm$ 0.11) (Lavoie et al. 2013). Accordingly, TMFs (MeHg: 2.3, THg: 1.2) also were at the lower end of the range for freshwater systems (MeHg: $8.3 \pm 7.5$, THg: $4.3 \pm 4.8$; Lavoie et al. 2013).
The far larger BCF than BMF values illustrate that processes at the base of the food web have a greater influence than trophic transfer on overall $\mathrm{MeHg}$ concentrations of higher consumers. At all 35 sites in our study, the magnitude of change in $\mathrm{MeHg}$ was greatest from water to organisms and declined from primary producers to consumers and further again from primary consumers to predators. This pattern is consistent with results of other studies, which showed that bioconcentration from water to algae is several orders of magnitude larger than biomagnification from algae to successively higher trophic levels (Weiner et al. 2007, Chasar et al. 2009) and places renewed emphasis on understanding controls on the delivery and uptake of $\mathrm{MeHg}$ from water to periphyton in aquatic systems.

Impoundment of stream channels by beavers increases baseline MeHg concentrations (Painter et al. 2015). However, beaver effects were partly offset by reductions in $\mathrm{MeHg}$ transfer among trophic levels within the food web when baseline $\mathrm{MeHg}$ concentration is high, and BCFs and BAFs did not change from up- to downstream of the ponds. Potential explanations include the high variability in water $\mathrm{MeHg}$ concentrations entering the ponds (Painter et al. 2015) and the strong effect of water $\mathrm{MeHg}$ concentrations on rates of uptake (Fig. 4A). The influence of the increase of water $\mathrm{MeHg}$ concentrations might have arisen from the absence of an accompanying increase of other basal foodweb resources (nutrients, algal and invertebrate biomass) downstream of the impoundments (Painter et al. 2015), which might have altered bioaccumulation via growth dilution (Ward et al. 2010). Nevertheless, MeHg concentrations in water and the

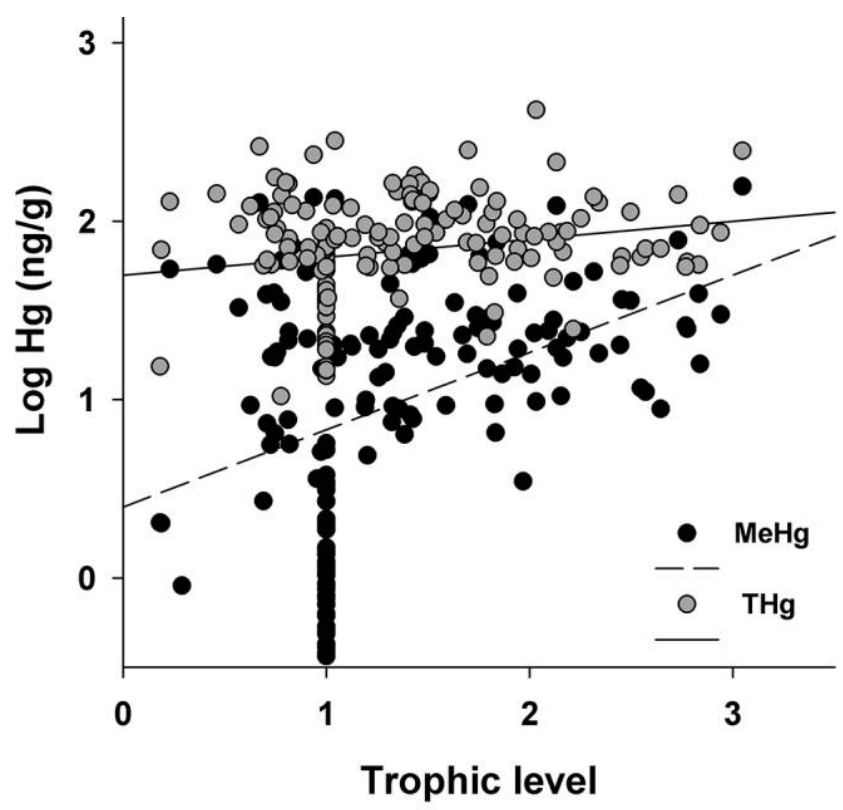

Figure 1. $\log \mathrm{Hg}$ concentration vs trophic level for methylmercury $(\mathrm{MeHg})$ (slope $=0.34)$ and total $\mathrm{Hg}(\mathrm{THg})$ (slope $=$ 0.08 ) in Rocky Mountain stream food webs. 


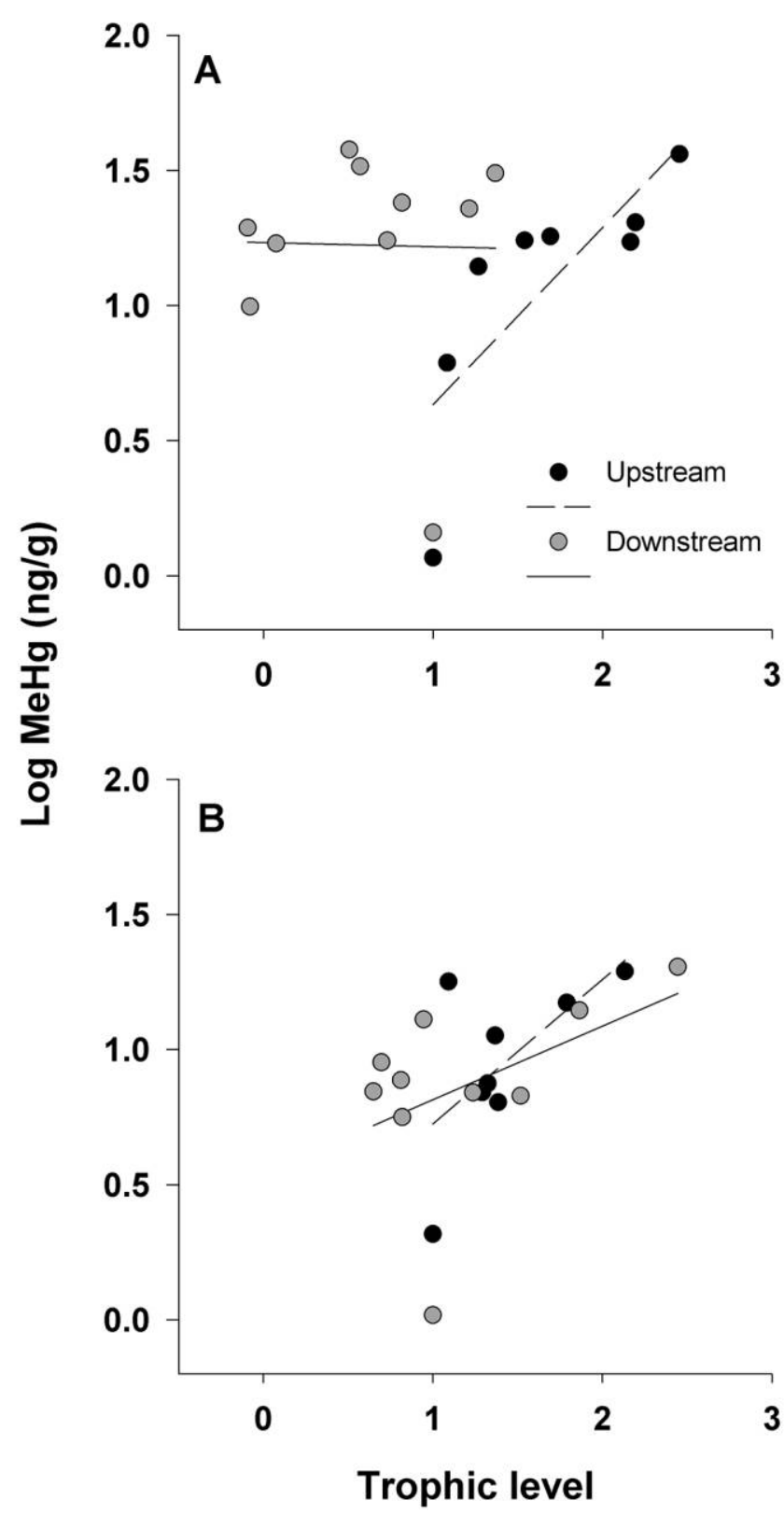

Figure 2. Log methylmercury (MeHg) concentration vs trophic level at locations up- and downstream of beaver impoundments at sites BEV004 (A) and BEV028 (B) where comprehensive food web sampling was undertaken.

diet strongly influenced bioaccumulation, and BCFs and BMFs were low when $\mathrm{MeHg}$ available for uptake was high. $\mathrm{pH}$ effects on $\mathrm{Hg}$ concentrations in streams in New Brunswick, Canada, were damped in intermediate trophic levels (primary consumers and predators) of invertebrate food webs because of inefficient $\mathrm{Hg}$ transfer (low BMFs) when dietary $\mathrm{MeHg}$ concentrations were high (Jardine et al. 2013). In our study streams, DOC appeared in our top models for predicting $\mathrm{MeHg}$ accumulation with a positive coefficient, but its effect generally was weak and did not differ from up- to downstream of ponds (Painter et al. 2015). In other systems, DOC increased significantly from up- to downstream of beaver ponds (Roy et al. 2009), suggesting potential for greater $\mathrm{MeHg}$ biomagnification at downstream sites. Thus, in locations where baseline $\mathrm{MeHg}$ concentrations and nutrients are high, beaver activity may have widereaching impacts on stream ecosystems, but prevailing chemical conditions may lead to attenuated effects on $\mathrm{MeHg}$ transfer further up the food chain.

Data from the comprehensive foodweb sites suggested that $\mathrm{MeHg}$ was taken up by periphyton and invertebrates more efficiently at the lower upstream than at the higher downstream concentrations (Painter et al. 2015). These data are consistent with the inverse relationship between concentration and uptake observed for laboratory-reared organisms (Tsui and Wang 2004, DeForest et al. 2007) and grazers and predators in New Brunswick streams (Jardine et al. 2013). Tsui and Wang (2004) suggested that the inverse relationship might be explained by saturation of binding sites for $\mathrm{MeHg}$ at high concentrations combined with slow turnover. In our study, $\mathrm{MeHg}$ was readily taken up into the food web even when water concentrations were $\mathrm{BDL}$, and BCFs were highest when concentrations were low. Our model analysis further indicates that $\mathrm{MeHg}_{\text {diet }}$ was negatively related to BMFs, especially from grazers to predators. Lavoie et al. (2013) found that MeHg TMSs were lowest when baseline TL Hg and atmospheric Hg deposition were highest.

DOC and baseline $\mathrm{MeHg}$ concentrations were positively related in our study streams (Painter et al. 2015), a pattern that has been well described in aquatic systems (Driscoll et al. 1995). Wetlands are major locations of $\mathrm{Hg}$ methylation, and DOC in streams is associated with the presence of wetlands in the surrounding watershed. DOC$\mathrm{Hg}$ complexes wash into streams from the terrestrial environment (Brigham et al. 2009, Chasar et al. 2009). However, DOC-Hg relationships are variable across systems. For example, our study streams receive low DOC inputs, and DOC is weakly positively associated with BMFs (e.g., $\mathrm{BMF}_{\text {(grazers/periphyton) }}$ rises from $\sim 3$ to $\sim 50$ along the low DOC gradient; Fig. 4E). BMFs for Ephemeroptera and Plecoptera at streams in a higher-DOC landscape in New Brunswick (Jardine et al. 2012) were lower (mean $\pm \mathrm{SE}=11 \pm 7$; Jardine et al. 2013) and not related to DOC (data not shown). This comparison suggests that DOC enhances biomagnification of $\mathrm{MeHg}$ through the food web at low concentrations but may inhibit trophic transfer at higher concentrations. Driscoll et al. (1995) reported that $\mathrm{MeHg}$ in fish was positively correlated with DOC at low concentrations $(<10 \mathrm{mg} / \mathrm{L})$ but declined when DOC was very high $(>30 \mathrm{mg} / \mathrm{L})$.

The difference in TL from prey to consumer can affect BMFs. For example, some concentrations were unexplained by BMF alone in a study of contaminant biomagnification in an Arctic ecosystem (Dietz et al. 2000), and the authors speculated that trophic linkages played a role. The increase 


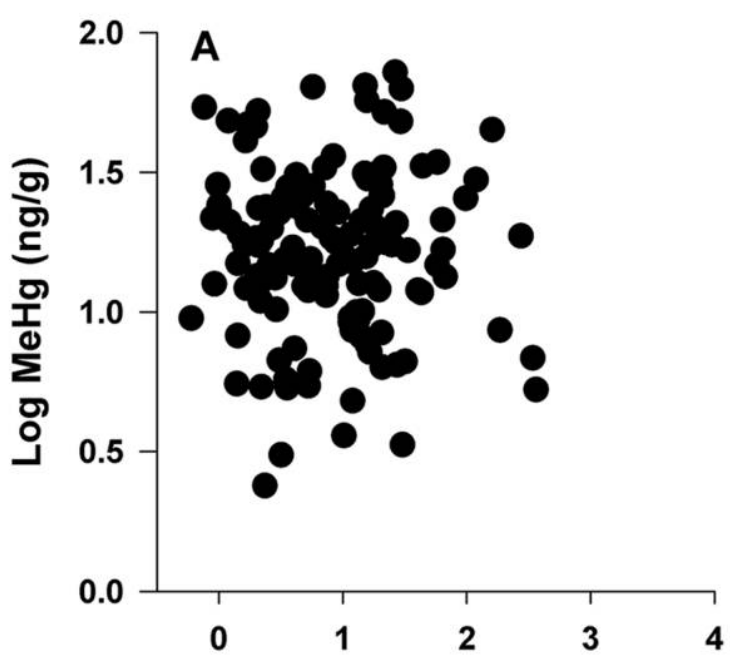

Log body size (mg)

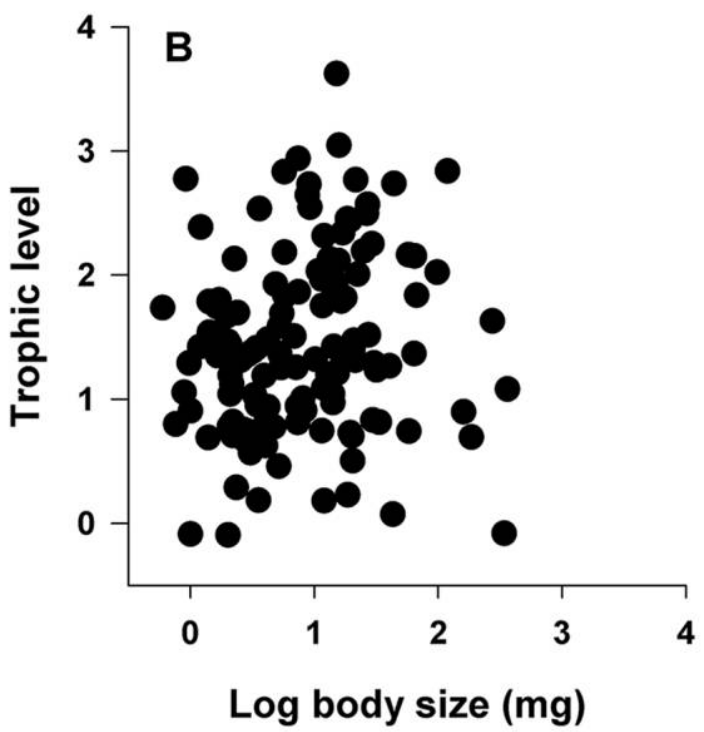

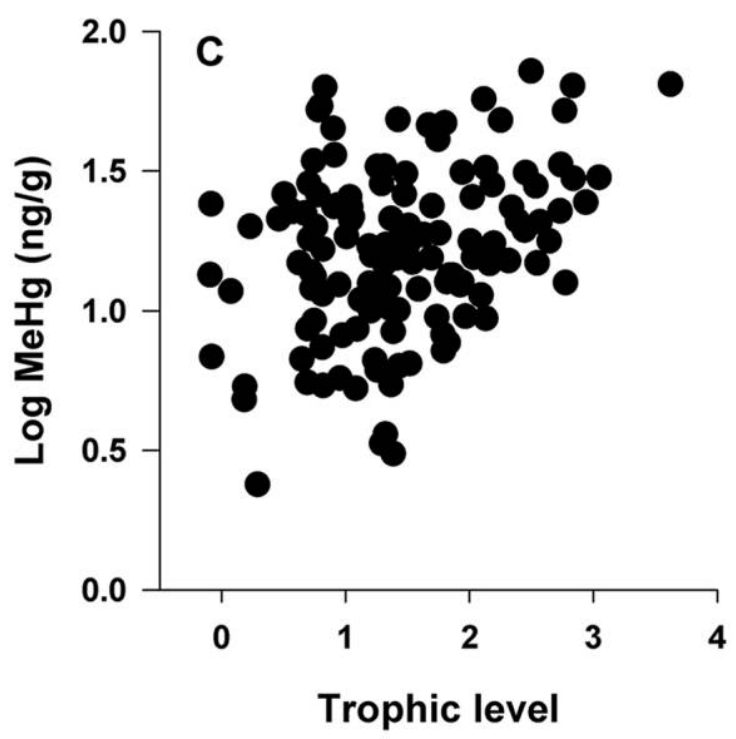

Figure 3. Log methylmercury (MeHg) concentration vs log body size (A), trophic level vs log body size (B), and log MeHg concentration vs trophic level (C) for invertebrates at 21 Rocky Mountain streams $(n=131)$.

in TL from prey to predator is associated with an increase in contaminant concentration; i.e., the TL-Hg relationship is significant overall (Kidd et al. 1995). Thus, trophic transfer of $\mathrm{Hg}$ should be greater when the step up in TL is greater for a given predator/prey pair. When calculating trophic transfer, care should be taken when selecting the TEF because TMFs are sensitive to changes in the TEF value used (Lavoie et al. 2013). For example, the use of a commonly applied TEF of 3.4\%o (Minagawa and Wada 1984, Post 2002) would result in TMFs of 4.06 for $\mathrm{MeHg}$ and 1.27 for $\mathrm{THg}$ in our food webs, effectively doubling the rate of biomagnification of $\mathrm{MeHg}$ from what we calculated based on a TEF of $2.0 \%$
$\mathrm{Hg}$ bioaccumulation models were largely developed for pelagic freshwater systems (Watras et al. 1998), where size structuring by gape limitation in fishes is strong. However, these models do not necessarily apply to stream food webs, where invertebrates are diverse and occupy many different niches, which results in weak size structuring and short food chains (Vander Zanden and Fetzer 2007, Watanabe et al. 2008, Riede et al. 2011). For example, body size increased significantly with trophic position in stream invertebrate food webs in tropical, subtropical, and temperate regions (Jardine 2014), but the relationships were weak compared to relationships in strongly size-structured food webs commonly found in the pelagic zone of temperate lakes (Hairston 
Table 3. Model sets used to account for variation in biomagnification factors (BMFs) for periphyton to grazers (model set A) and grazers to predators (model set B). $\Delta_{i}$ is the difference between the Akaike Information Criterion for small sample size (AICc) value of the best model and a competing model. $w_{i}$ is the Akaike weight, with the highest ranked model in the set having the highest $w_{i}$. Evidence ratios are a measure of likelihood of the best model over competing models. Models shown are those used for model averaging with $\Delta \leq 7 . \mathrm{TL}=$ trophic level, $\mathrm{DOC}=$ dissolved organic $\mathrm{C}, \mathrm{TP}=$ total $\mathrm{P}$, chl $a=$ chlorophyll $a$. See Table 1 for other abbreviations.

\begin{tabular}{|c|c|c|c|c|}
\hline Model set & Model & $\Delta_{i}$ & $w_{i}$ & Evidence ratio \\
\hline \multirow[t]{10}{*}{ A) $\mathrm{BMF}_{\text {(grazers/periphyton) }}$} & $\mathrm{TL}_{\text {(grazers/periphyton) }}$ & 0.000 & 0.259 & - \\
\hline & $\mathrm{TL}_{\text {(grazers/periphyton) }}, \mathrm{DOC}$ & 0.066 & 0.251 & 1.034 \\
\hline & $\mathrm{MeHg}_{\text {diet, }}, \mathrm{TL}_{\text {(grazers/periphyton), }}$ DOC & 0.588 & 0.193 & 1.342 \\
\hline & DOC & 1.791 & 0.106 & 2.449 \\
\hline & $\mathrm{MeHg}_{\text {diet }}, \mathrm{TL}_{\text {(grazers/periphyton) }}$ & 3.138 & 0.054 & 4.803 \\
\hline & $\mathrm{MeHg}_{\text {diet }}, \mathrm{DOC}$ & 3.317 & 0.049 & 5.252 \\
\hline & Intercept only & 3.909 & 0.037 & 7.059 \\
\hline & $\mathrm{MeHg}_{\text {diet }}, \mathrm{TL}_{\text {(grazers/periphyton), }} \mathrm{DOC}$, chl $a$ & 4.402 & 0.029 & 9.032 \\
\hline & $\mathrm{MeHg}_{\text {diet }}$ & 6.421 & 0.010 & 24.792 \\
\hline & DOC, TP, chl $a$ & 6.765 & 0.009 & 29.442 \\
\hline \multirow[t]{9}{*}{ B) $\mathrm{BMF}_{\text {(predators/grazers) }}$} & $\mathrm{MeHg}_{\text {diet }}, \mathrm{DOC}$ & 0.000 & 0.456 & - \\
\hline & $\mathrm{MeHg}_{\text {diet }}, \mathrm{DOC}, \operatorname{chl} a$ & 0.257 & 0.401 & 1.137 \\
\hline & $\mathrm{MeHg}_{\text {diet }}$ & 3.120 & 0.096 & 4.759 \\
\hline & $\mathrm{MeHg}_{\text {diet }}, \operatorname{chl} a$ & 5.796 & 0.025 & 18.136 \\
\hline & $\mathrm{TL}_{\text {(predators/grazers) }}$ & 7.107 & 0.013 & 34.932 \\
\hline & $\mathrm{MeHg}_{\text {diet }}, \mathrm{DOC}, \mathrm{TP}, \mathrm{chl} a$ & 8.988 & 0.005 & 89.483 \\
\hline & $\mathrm{MeHg}_{\text {diet }}, \mathrm{TL}_{\text {(predators/grazers) }}$ & 11.274 & 0.002 & 280.630 \\
\hline & $\mathrm{MeHg}_{\text {diet, }}, \mathrm{TL}_{\text {(predators/grazers) }}, \mathrm{DOC}$ & 11.876 & 0.001 & 379.108 \\
\hline & Intercept only & 12.995 & 0.001 & 663.349 \\
\hline
\end{tabular}

and Hairston 1993). The implication of this weak size structuring is that larger animals may not necessarily have the highest $\mathrm{Hg}$ concentrations nor occupy the highest TLs (Watanabe et al. 2008). At the comprehensive foodweb sites in our study, Tipulidae have low $\mathrm{MeHg}$ concentrations, low TLs, and the largest body sizes, whereas smaller invertebrates, particularly grazing mayflies, have the highest $\mathrm{MeHg}$ levels suggesting that other factors drive accumulation of $\mathrm{MeHg}$ in these organisms. In a study by Mason et al. (2000), smaller invertebrates had higher concentrations of As and
Se, probably because their high surface area:volume ratios increased absorptive surface area relative to that of larger organisms, but findings for $\mathrm{Hg}$ were inconsistent. The relative contributions of dermal absorption and dietary uptake are less well understood for small invertebrates than fishes (Hall et al. 1997).

Small-bodied omnivores can have higher-than-expected TLs. Invertebrates can exhibit both obligate and facultative functional feeding behavior and may undergo ontogenetic shifts in feeding habits (Cummins and Klug 1979). Hepta-

Table 4. Partitioned- $R^{2}$ based relative variable importance (RVI) metrics $I_{\text {global }}$ and $I_{\text {weighted }}$ for model sets A $\left(\mathrm{BMF}_{\text {(grazers/periphyton) }}\right)$ and $\mathrm{B}\left(\mathrm{BMF}_{\text {(predators/grazers) }}\right)$ showing the decomposition of variance among explanatory variables dietary methylmercury $\left(\mathrm{MeHg}_{\text {diet }}\right)$, trophic level of consumers relative to their prey $\left(\mathrm{TL}_{\text {(consumer/prey) }}\right)$, dissolved organic C (DOC), total P (TP), and benthic chlorophyll $a(\mathrm{chl} a)$.

\begin{tabular}{lcccrr}
\hline RVI Metric & $\mathrm{MeHg}_{\text {(diet) }}$ & $\mathrm{TL}_{\text {(consumer/prey) }}$ & $\mathrm{DOC}$ & $\mathrm{TP}$ & $\mathrm{Chl} a$ \\
\hline $\begin{array}{l}\text { Model set A } \\
I_{\text {global }}\end{array}$ & 0.041 & 0.223 & 0.180 & 0.037 & 0.006 \\
$\quad I_{\text {weighted }}$ & 0.012 & 0.198 & 0.122 & 0.001 & $<0.001$ \\
Model set B & & & & & \\
$I_{\text {global }}$ & 0.397 & 0.251 & 0.148 & 0.022 & 0.039 \\
$I_{\text {weighted }}$ & 0.744 & 0.007 & 0.069 & $<0.001$ & 0.018 \\
\hline
\end{tabular}



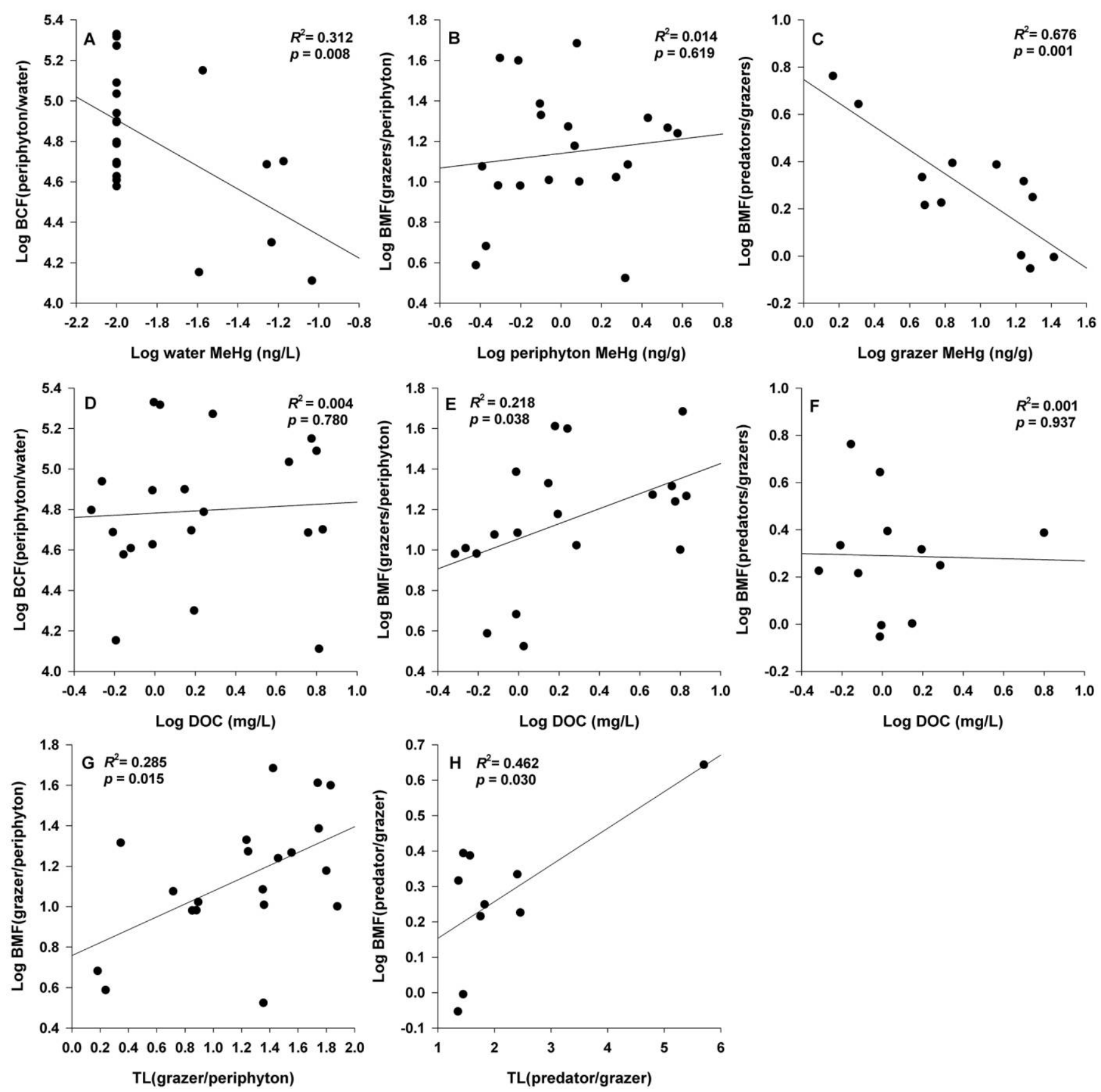

Figure 4. Linear regressions show the strength of relationships for log bioconcentration factor (BCF) vs log methylmercury ( $\mathrm{MeHg}$ ) concentration in water (A), log biomagnification factor (BMF) from periphyton to grazers (grazers/periphyton) vs log MeHg in periphyton (B), log BMF from grazers to predators (predators/grazers) vs log MeHg in grazers (C), $\log$ bioconcentration factor $(\mathrm{BCF})$ of water to periphyton (periphyton/water) vs log dissolved organic $\mathrm{C}(\mathrm{DOC})(\mathrm{D}), \log \mathrm{BMF}_{\text {(grazers/periphyton) }}$ vs $\log \mathrm{DOC}(\mathrm{E}), \log$ $\mathrm{BMF}_{\text {(predators/grazers) }}$ vs $\log \mathrm{DOC}(\mathrm{F}), \log \mathrm{BMF}_{\text {(grazers/periphyton) }}$ vs trophic level difference (TL) between periphyton and grazers (grazer/ periphyton) $(\mathrm{G})$, and $\log \mathrm{BMF}_{\text {(predators/grazers) }} \mathrm{vs} \mathrm{TL}_{\text {(predators/grazers) }}(\mathrm{H})$.

geniid and Ephemerellid mayflies are classified as herbivorous scrapers (Merritt and Cummins 1996) but can be facultative collectors. Baetids also can be facultative feeders. They have the potential to collect particles "of animal origin" or bacteria and, therefore, may occupy a higher tro- phic position than expected as a consequence of omnivory (Anderson and Cabana 2007). The potential for omnivory increases the utility of stable isotopes in bioaccumulation studies, particularly when establishing the relative difference in $\mathrm{TL}$ from prey to consumer $\left(\mathrm{TL}_{\text {consumer/prey }}\right)$. For example, 
in our study, some grazing mayflies had higher $\delta^{15} \mathrm{~N}$ than presumed predators resulting in $\mathrm{TL}_{\text {(predators/grazers) }}$ that were $<1$ (data not shown), and ephemerellids occupied the same TL as predators at 2 upstream beaver sites (data not shown). Altered size-TL-Hg relationships have implications for trophic transfer because less $\mathrm{Hg}$ than expected will transfer up the food chain if fish tend to eat larger invertebrates and larger invertebrates have lower $\mathrm{Hg}$.

Trophic transfer is more efficient at low than high environmental $\mathrm{MeHg}$ concentrations, but our results suggest that $\mathrm{MeHg}$ in top predators is governed more by supply of $\mathrm{MeHg}$ at the base of the food web than by trophic transfer and trophic efficiency (Chasar et al. 2009). Hg enters ecosystems largely as $\mathrm{Hg}(\mathrm{II})$, whereas $\mathrm{MeHg}$ production and subsequent uptake into algae occurs within the system and is highly variable (Driscoll et al. 2013). Concentrations of $\mathrm{MeHg}$ in predatory fishes can remain elevated for years following impoundment and flooding of large reservoirs because of release of $\mathrm{Hg}$ from soils and vegetation (St Louis et al. 2004, Hall et al. 2005). In addition, atmospheric deposition of $\mathrm{Hg}$ is strongly linked to $\mathrm{Hg}$ concentrations in fish (Harris et al. 2007). Anthropogenic emissions contribute $2 / 3$ of all atmospheric deposition (Hammerschmidt and Fitzgerald 2006) and affect fish populations that are far from any direct emissions source. Decreases in $\mathrm{Hg}$ emissions are predicted to lead to rapid declines in fish concentrations (Harris et al. 2007). These examples, taken together with our findings, further highlight the importance of processes at the base of the food web in driving uptake and trophic transfer of Hg. The relative importance of supply vs uptake and transfer in determining $\mathrm{Hg}$ in organisms at higher TLs is important because inputs are more readily managed than transfers through the food web.

\section{ACKNOWLEDGEMENTS}

This research was supported by funding from the Alberta Conservation Association Grants in Biodiversity program, the National Science and Engineering Research Council, and the Canadian Foundation for Innovation. The authors thank Cherie Westbrook, Britt Hall, Nelson O'Driscoll, Jeff Hudson, and 2 anonymous referees for constructive comments on earlier versions of this work.

\section{LITERATURE CITED}

Adams, R. M., M. R. Twiss, and C. T. Driscoll. 2009. Patterns of mercury accumulation among seston in lakes of the Adirondack Mountains, New York. Environmental Science and Technology 43:4836-4842.

Anderson, C., and G. Cabana. 2007. Estimating the trophic position of aquatic consumers in river food webs using nitrogen stable isotopes. Journal of the North American Benthological Society 26:273-285.

Anderson, C., and G. Cabana. 2009. Anthropogenic alterations of lotic food web structure: evidence from the use of nitrogen isotopes. Oikos 118:1929-1939.
Arnot, J. A., and F. A. P. C. Gobas. 2006. A review of bioconcentration factor (BCF) and bioaccumulation factor (BAF) assessments for organic chemicals in aquatic organisms. Environmental Reviews 14:247-297.

Borgå, K., K. A. Kidd, D. C. G. Muir, O. Berglund, J. M. Conder, F. A. P. C. Gobas, J. Kucklik, O. Malm, and D. E. Powell. 2011. Trophic magnification factors: considerations of ecology, ecosystems and study design. Integrated Environmental Assessment and Management 8:64-84.

Brigham, M. E., D. A. Wentz, G. R. Aiken, and D. P. Krabbenhoft. 2009. Mercury cycling in stream ecosystems. 1. Water column chemistry and transport. Environmental Science and Technology 43:2720-2725.

Bunn, S. E., C. Leigh, and T. D. Jardine. 2013. Diet-tissue fractionation of $\delta^{15} \mathrm{~N}$ by consumers from streams and rivers. Limnology and Oceanography 58:765-773.

Burnham, K. P., and D. R. Anderson. 2002. Model selection and multimodel inference. 2nd edition. Springer, New York.

Cabana, G., and J. B. Rasmussen. 1996. Comparison of aquatic food chains using nitrogen stable isotopes. Proceedings of the National Academv of Sciences of the United States of America 93:10844-10847.

Cardwell, R. D., D. K. DeForest, K. V. Brix, and W. J. Adams. 2013. Do $\mathrm{Cd}, \mathrm{Cu}, \mathrm{Ni}, \mathrm{Pb}$, and $\mathrm{Zn}$ biomagnify in aquatic ecosystems? Reviews of Environmental Contamination and Toxicology 226:101-122.

CEPA (Canadian Environmental Protection Act). 1999 (S.C. 1999, c. 33). Government of Canada, Ottawa, Canada. (Available from: http://www.ec.gc.ca/lcpe-cepa/)

Chasar, L. C., B. C. Scudder, A. R. Stewart, A. H. Bell, and G. R. Aiken. 2009. Mercury cycling in stream ecosystems. 3. Trophic dynamics and methylmercury bioaccumulation. Environmental Science and Technology 43:2733-2739.

Cummins, K. W., and M. J. Klug. 1979. Feeding ecology of stream invertebrates. Annual Review of Ecology and Systematics 10:147-172.

DeForest, D. K., K. V. Brix, and W. J. Adams. 2007. Assessing metal bioaccumulation in aquatic environments: the inverse relationship between bioaccumulation factors, trophic transfer factors and exposure concentration. Aquatic Toxicology 84:236-246.

Dietz, R., F. Riget, M. Cleemann, A. Aarkrog, P. Johansen, and J. C. Hansen. 2000. Comparisons of contaminants from different trophic levels and ecosystems. Science of the Total Environment 245:221-231.

Dittman, J. A., and C. T. Driscoll. 2009. Factors influencing changes in mercury concentrations in lake water and Yellow Perch (Perca flavescens) in Adirondack lakes. Biogeochemistry 93:179-196.

Driscoll, C. T., V. Blette, C. Yan, C. L. Schofield, R. Munson, and J. Holsapple. 1995. The role of dissolved organic carbon in the chemistry and bioavailability of mercury in remote Adirondack lakes. Water, Air, and Soil Pollution 80:499-508.

Driscoll, C. T., R. P. Mason, H. M. Chan, D. J. Jacob, and N. Pirrone. 2013. Mercury as a global pollutant: sources, pathways, and effects. Environmental Science and Technology 47: 4967-4983.

Fisk, A. T., K. A. Hobson, and R. J. Norstrom. 2001. Influence of chemical and biological factors on trophic transfer of persis- 
tent organic pollutants in the Northwater Polynya marine food web. Environmental Science and Technology 35:732-738.

Gewurtz, S. B., S. P. Bhavsar, and R. Fletcher. 2011. Influence of fish size and sex on mercury/PCB concentration: importance for fish consumption advisories. Environment International $37: 425-434$

Giam, X., and J. D. Olden. 2015. Quantifying variable importance in a multimodel inference framework. Methods in Ecology and Evolution 7:388-397.

Gobas, F. A. P. C., W. de Wolf, L. P. Burkhard, E. Verbruggen, and K. Plotzke. 2009. Revisiting bioaccumulation criteria for POPs and PBT assessments. Integrated Environmental Assessment and Management 5:624-637.

Gobas, F. A. P. C., and H. A. Morrison. 2000. Bioconcentration and biomagnification in the aquatic environment. Pages 189231 in R. S. Boethling and D. Mackay (editors). Handbook of property estimation methods for chemicals: environmental and health sciences. CRC Press, Boca Raton, Florida.

Grömping, U. 2015. Package 'relaimpo': relative importance of regressors in linear models. R package version 2.2-2. R Project for Statistical Computing, Vienna, Austria. (Available from: http://cran.r-project.org/web/packages/relaimpo/index.html)

Hairston, N. G., and N. G. Hairston. 1993. Cause-effect relationships in energy flow, trophic structure, and interspecific interactions. American Naturalist 142:379-411.

Hall, B. D., R. A. Bodaly, R. J. P. Fudge, J. W. M. Rudd, and D. M. Rosenberg. 1997. Food as the dominant pathway of methylmercury uptake by fish. Water, Air, and Soil Pollution 100: $13-24$.

Hall, B. D., V. L. St. Louis, K. R. Rolfhus, R. A. Bodaly, K. G. Beaty, M. J. Paterson, and K. A. Peech Cherewyk. 2005. Impacts of reservoir creation on the biogeochemical cycling of methylmercury and total mercury in boreal upland forests. Ecosystems 8:248-266.

Hammerschmidt, C. R., and W. F. Fitzgerald. 2006. Methylmercury in freshwater fish linked to atmospheric mercury deposition. Environmental Science and Technology 40:77647770.

Harris, R. C., J. W. M. Rudd, M. Amyot, C. L. Babiarz, K. G. Beaty, P. J. Blanchfield, R. A. Bodaly, B. A. Branfireun, C. G. Gilmour, J. A. Graydon, A. Heyes, H. Hintelmann, J. P. Hurley, C. A. Kelly, D. P. Krabbenhoft, S. E. Lindberg, R. P. Mason, M. J. Paterson, C. L. Podemski, A. Robinson, K. A. Sandilands, G. R. Southworth, V. L. St Louis, and M. T. Tate. 2007. Whole ecosystem study shows rapid fish-mercury response to changes in mercury deposition. Proceedings of the National Academy of Sciences of the United States of America 104:16586-16591.

Helsel, D. R. 2005. Nondetects and data analysis: statistics for censored environmental data. John Wiley and Sons, Hoboken, New Jersey.

Jardine, T. D. 2014. Organic matter sources and size structuring in stream invertebrate food webs across a tropical to temperate gradient. Freshwater Biology 59:1509-1521.

Jardine, T. D., K. A. Kidd, and N. O’Driscoll. 2013. Food web analysis reveals effects of $\mathrm{pH}$ on mercury bioaccumulation at multiple trophic levels in streams. Aquatic Toxicology 132/ 133:46-52.

Jardine, T. D., K. A. Kidd, and J. B. Rasmussen. 2012. Aquatic and terrestrial organic matter in the diet of stream consumers: implications for mercury bioaccumulation. Ecological Applications 22:843-855.

Kidd, K. A., R. H. Hesslein, R. J. P. Fudge, and K. A. Hallard. 1995. The influence of trophic level as measured by $\delta \mathrm{N}$ on mercury concentrations in freshwater organisms. Pages 10111015 in D. B. Porcella, J. W. Huckabee, and B. Wheatley (editors). Mercury as a global pollutant. Springer, Dordrecht, The Netherlands.

Lavoie, R. A., T. D. Jardine, M. M. Chumchal, K. A. Kidd, and L. M. Campbell. 2013. Biomagnification of mercury in aquatic food webs: a worldwide meta-analysis. Environmental Science and Technology 47:13385-13394.

Lee, L. 2013. NADA: nondetects and data analysis for environmental data. R package version 1.5-6. R Project for Statistical Computing, Vienna, Austria. (Available from: http:// CRAN.R-project.org $/$ package $=$ NADA)

Mason, R. P., J.-M. Laporte, and S. Andres. 2000. Factors controlling the bioaccumulation of mercury, methylmercury, arsenic, selenium, and cadmium by freshwater invertebrates and fish. Archives of Environmental Contamination and Toxicology 38:283-297.

McCutchan, J. H., W. M. Lewis, Jr, C. Kendall, and C. C. McGrath. 2003. Variation in trophic shift for stable isotope ratios of carbon, nitrogen, and sulfur. Oikos 102:378-390.

McGeer, J. C., K. V. Brix, J. M. Skeaff, D. K. DeForest, S. I. Brigham, W. J. Adams, and A. Green. 2003. Inverse relationship between bioconcentration factor and exposure concentration for metals: implications for hazard assessment of metals in the aquatic environment. Environmental Toxicologv and Chemistry 22:1017-1037.

Mergler, D., H. A. Anderson, L. H. M. Chan, K. R. Mahaffey, M. Murray, M. Sakamoto, and A. H. Stern. 2007. Methylmercury exposure and health effects in humans: a worldwide concern. Ambio 36:3-11.

Merritt, R. W., and K. W. Cummins (editors). 1996. An introduction to the aquatic insects of North America. Kendall/ Hunt, Dubuque, Iowa.

Minagawa, M., and E. Wada. 1984. Stepwise enrichment of N along food chains: further evidence and relation between $\delta^{15} \mathrm{~N}$ and animal age. Geochimica et Cosmochimica Acta 48:1135-1140.

Painter, K. J., C. J. Westbrook, B. D. Hall, N. J. O’Driscoll, and T. D. Jardine. 2015. Effects of in-channel beaver impoundments on mercury bioaccumulation in Rocky Mountain stream food webs. Ecosphere 6:194.

Post, D. M. 2002. Using stable isotopes to estimate trophic position: models, methods, and assumptions. Ecology 83:703718.

Riede, J. O., U. Brose, B. Ebenman, U. Jacob, R. Thompson, C. R. Townsend, and T. Jonsson. 2011. Stepping in Elton's footprints: a general scaling model for body masses and trophic levels across ecosystems. Ecology Letters 14:169-178.

Roy, V., M. Amyot, and R. Carignan. 2009. Beaver ponds increase methylmercury concentrations in Canadian Shield streams along vegetation and pond-age gradients. Environmental Science and Technology 43:5605-5611.

St Louis, V. L., J. W. M. Rudd, C. A. Kelly, R. A. Bodaly, M. J. Paterson, K. G. Beaty, R. H. Hesslein, A. Heyes, and A. R. Majewski. 2004. The rise and fall of mercury methylation in 
an experimental reservoir. Environmental Science and Technology 38:1348-1358.

Tsui, M. T. K., and W. X. Wang. 2004. Uptake and elimination routes of inorganic mercury and methylmercury in Daphnia magna. Environmental Science and Technology 38:808-816.

Vander Zanden, M. J., and W. W. Fetzer. 2007. Global patterns of aquatic food chain length. Oikos 116:1378-1388.

Ward, D. M., K. H. Nislow, and C. L. Folt. 2010. Bioaccumulation syndrome: identifying factors that make some stream food webs prone to elevated mercury bioaccumulation. Annals of the New York Academy of Science 1195:62-83.

Watanabe, K., M. T. Monaghan, Y. Takemon, and T. Omura. 2008. Biodilution of heavy metals in a stream macroinver- tebrate food web: evidence from stable isotope analysis. Science of the Total Environment 394:57-67.

Watras, C. J., R. C. Back, S. Halvorsen, R. J. M. Hudson, K. A. Morrison, and S. P. Wente. 1998. Bioaccumulation of mercury in pelagic freshwater food webs. Science of the Total Environment 219:183-208.

Weiner, J. G., R. A. Bodaly, S. S. Brown, M. Lucotte, M. C. Newman, D. B. Porcella, R. J. Reash, and E. B. Swain. 2007. Monitoring and evaluating trends in methylmercury accumulation in aquatic biota. Pages 87-112 in R. C. Harris, D. P. Krabbenhoft, R. P. Mason, M. W. Murray, R. J. Reash, and T. Saltman (editors). Ecosystem responses to mercury contamination: indicators of change. CRC Press, Boca Raton, Florida. 